\title{
Skin conductance level as a function of time after shock
}

\author{
ANNE MENOFF, ARCHIE CARRAN, and WILLIAM I. RIDDELL \\ State University of New York, Brockport, New York 14420
}

The effect of time after shock on conductance level of the rat was assessed at $0 \mathrm{sec}, 30 \mathrm{sec}, 2 \mathrm{~min}$, $15 \mathrm{~min}, 30 \mathrm{~min}$, and $1 \mathrm{~h}$ following shock. The results indicated that, although the time after shock is a significant factor in conductance level, the relationship is not linear, and the greatest increase in conductance is still present $15 \mathrm{~min}$ following the termination of the shock.

While the evidence that skin resistance level is modified by aversive stimuli is clear (Campbell \& Teghtsoonian, 1958; Carran, Yeudall, \& Royce, 1964; Walters \& Tullis, 1966), no evidence concerning the relationship of conductance level to time after the presentation of the aversive stimulus has been established. Since this measure has been suggested as a useful tool to denote emotional arousal (Walters \& Tullis, 1966), it is essential to note the time course of this response following aversive stimulation. This is particularly important in light of the fact that shock is employed extensively as an aversive stimulus, and intertrial intervals are not consistent across studies. The purpose of the present study is, therefore, to gain evidence concerning the relationship between conductance level and time after shock and to further note the total time necessary for conductance level to reach basal level following shock.

\section{METHOD}

\section{Subjects}

The subjects were 10 naive adult female Holtzman rats. All subjects were housed individually and maintained on ad lib food and water during the course of the experiment.

\section{Apparatus}

The subjects were tested in a $53.8 \times 10.2 \times 24.2 \mathrm{~cm}$ Plexiglas compartment, the grid floor of which was constructed of .32-cm-diam stainless steel rods $1.28 \mathrm{~cm}$ apart. An oscilloscope was connected in parallel across a $24 \mathrm{~K}$ sensing resistor to the grid floor via a manual switch. A 4-V dc sensing current was employed, and a $71 \mathrm{~K}$ resistor was put in series with the subject. The shock voltage was $750 \mathrm{~V}$. Skin conductance was recorded in the unrestrained subject, with the grid bars of the test chamber serving as recording electrodes. The grid floor was thoroughly cleaned between subjects and the temperature and humidity remained reasonably constant during the course of testing.

\section{Procedure}

The 10 subjects were randomly divided between the shock and no-shock groups. The subjects were placed in the testing

Reprints may be obtained from William Riddell, Department of Psychology, State University of New York, Brockport, New York 14420. The second author is deceased. chamber for $2 \mathrm{~h}$ of adaptation directly preceding experimentation. Following the adaptation period, the subjects in the shock condition received a shock of $750 \mathrm{~V}$ for $2 \mathrm{sec}$. Conductance levels were assessed for both groups for 15 -sec intervals which were initiated $0 \mathrm{sec}, 30 \mathrm{sec}, 2 \mathrm{~min}, 15 \mathrm{~min}, 30 \mathrm{~min}$, and $1 \mathrm{~h}$ following the shock or, for the control group, following the adaptation period. One subject in the control group was discarded due to a procedural error. The subjects had free access to food and water throughout the adaptation period and experimental session.

\section{RESULTS AND DISCUSSION}

The results were analyzed in terms of conductance units which were calculated from the lowest resistance values at each of the six different $15-\mathrm{sec}$ sensing intervals. Figure 1 indicates the mean conductance value for each group at each interval. The conductance values are plotted at the mean time of each interval, i.e., the 0 -sec interval is plotted at $7.5 \mathrm{sec}$, the $30-\mathrm{sec}$ interval at $37.5 \mathrm{sec}$, etc. A 2 by 6 analysis of variance on the conductance scores across groups and time after shock indicated a significant condition effect $(F=32.41$, $\mathrm{df}=1 / 7, \mathrm{p}<.05)$. The effect of time after shock and and the interaction of Time by Condition failed to achieve significance. As is evident from Figure 1,

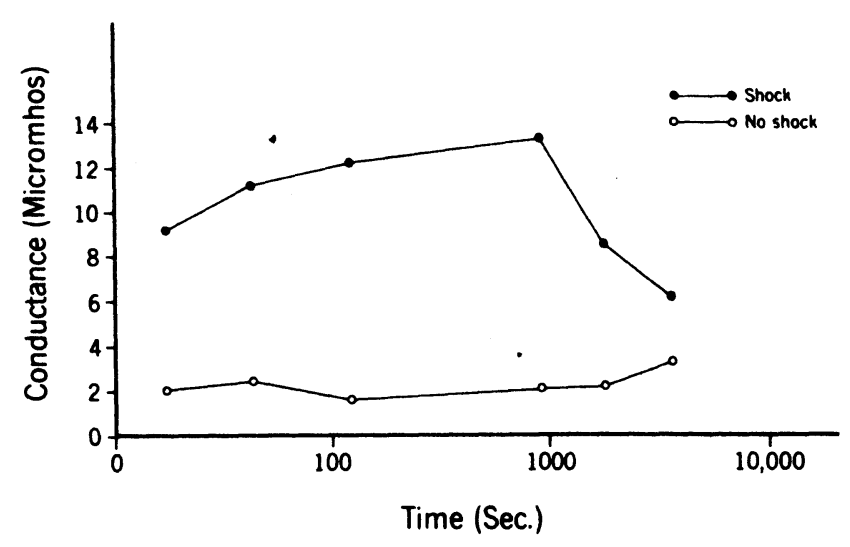

Figure 1. Skin conductance levels over each of the seven test intervals. 
however, the effect of time after shock in the shock condition is not a regularly decreasing function. Trend analyses computed for this group over the six test intervals showed that the linear component accounted for only $23 \%$ of the variability, while $68 \%$ of the variability was explained by the quadratic component $(F=9.12, \mathrm{df}=1 / 35, \mathrm{p}<.05)$. While the significant increase in conductance level following shock is consonant with previous investigations (Campbell \& Teghtsoonian, 1958; Carran et al, 1964), what is somewhat surprising is that conductance level neither reaches its maximum immediately following shock or shows a significant decrease until $30 \mathrm{~min}$ following the aversive stimulus. This pattern of results suggests, therefore, that one must wait at least $30 \mathrm{sec}$ following shock to get a measure of the maximum increase in conductance and maintain approximately $1-\mathrm{h}$ intertrial intervals.

\section{REFERENCES}

Campbell. G. A.. \& Teghtsoonian. R. Electrical and behavioral effects of different types of shock stimuli in the rat. Journal of Comparative and Physiological Psychology, 1958. 51. 185-192.

Carran. A. B., Yeudall, L. T.. \& Royce, J. R. Voltage level and skin resistance in avoidance conditioning of inbred strains of mice. Journal of Comparative and Physiological Psychologv, 1964. 38. 427-430.

WAiters, G., \& Tullis, C. Skin resistance changes in the rat during repeated encounters with electric shock. Psychonomic Science. 1\%66. 5. 359-360.

(Received for publication September 4. 1975.) 